\title{
CEREBRAL THROMBOANGIITIS OBLITERANS
}

\author{
BY \\ L. WOLMAN \\ From the Department of Neuropathology, Royal Infirmary, Sheffield
}

(RECEIVED FOR PUBLICATION MAY 15, 1957)

A stroke due to vascular occlusion in a young person can raise many diagnostic and prognostic problems. In the following case report hemiplegia of sudden onset occurred in a young man followed by partial recovery without a definite diagnosis being made, despite full investigation. Further progression of the disease leading to death two years later enabled a complete pathological investigation to be undertaken.

\section{Case Report}

A 26-year-old labourer was struck on the right side of the forehead on April 30,1952, by a 5-gallon can while loading it on to a wagon. He sustained a small cut, $6 \mathrm{~mm}$. in length, over the right eye and was able to continue at his work. About two hours later he had an epileptiform fit in which his speech became slurred and the left side of his body became weak. He had been in good health previously. There was a history of convulsions in early childhood, an injury to the left eye when 9 years old, and osteomyelitis of the jaw. when 13 years old. On admission to this hospital a week later he was found to have a profound left hemiplegia and hemianaesthesia which had remained unchanged since the fit. His blood pressure, blood count, and cerebrospinal fluid were normal. The Wassermann reaction was negative both in the blood and the cerebrospinal fluid. A right-sided percutaneous angiogram showed normal filling of the middle and anterior cerebral vessels. Air ventriculography outlined small narrowed ventricles, slightly displaced to the left of the midline. An E.E.G. showed a high-amplitude slow-wave focus in the right fronto-temporal region, consisting of 2 to $4 \mathrm{c}$./sec. waves. These findings were interpreted as being due to right-sided cerebral oedema in relation to an infarct or possibly an intracerebral blood clot.

When the air study was repeated three weeks later, the ventricles appeared in their normal position, but the right ventricle had become dilated, thus supporting the diagnosis of infarction. The E.E.G. at this time showed improvement on the previous record, with right-sided low-voltage slow waves. When repeated three months later the E.E.G. was normal. The left hemiplegia persisted with marked spasticity of the leg and flexion deformity of the hand. The only movement in the left upper limb was a slight elevation at the shoulder joint.
About 18 months after the first attack he had a further series of left-sided fits, despite being on anticonvulsant drugs. Several E.E.G. tracings at this time were normal. After a severe fit on February 9, 1954 , he remained incontinent and unable to speak or swallow. He now presented the picture of pseudo bulbar palsy, with bilateral increased reflexes and extensor plantar responses. He showed gross emotional lability with frequent episodes of depression and weeping. The E.E.G. showed irregular moderate amplitude 3 to $4 \mathrm{c}$. $/ \mathrm{sec}$. activity in the left frontal region. A repeat air encephalogram two weeks later was normal. The cerebrospinal fluid and blood pressure were again normal on examination. He continued to have occasional fits and his condition deteriorated. He died on May 5, 1954, three months after developing pseudo bulbar palsy and two years after the onset of his illness.

\section{Pathological Findings}

At necropsy, performed 18 hours after death, no evidence of injury was found apart from an old corneal opacity of the left eye which had been present since childhood. The body was thin but not wasted. The larynx and trachea were healthy. Both lungs showed basal congestion. The heart was normal in size and configuration, with healthy muscle and valves. The alimentary system, liver, spleen, and endocrine organs appeared healthy. Both kidneys contained several small wedgeshaped scars in the cortex with normal intervening tissue. The renal arteries were healthy. Slight patchy atheroma was present in the descending aorta. Several arteries, including the coronary, carotids with internal and external branches, subclavian, axillary, internal and external iliac, and femoral, were examined on both sides. All were healthy and free from atheroma.

Central Nervous System.-No abnormality of the skull or dura was seen. The pia arachnoid was thickened over both hemispheres, maximally over the fronto-parietal regions, where it was discoloured golden brown by haemosiderin pigment. The convolutions surrounding the upper part of both Sylvian fissures were shrunken and depressed below the adjacent gyri as a result of cystic 
softening (Figs. 1 and 2). The area affected was more extensive on the right side, extending deeply to involve the claustrum, external capsule, and putamen, whereas only the insular cortex and underlying white matter were included in the softening on the left side (Fig. 3). Similar but much smaller areas of old softening were present on the under surface of both occipital lobes. These had destroyed the fusiform gyri, more extensively on the right side than the left. The vessels of the circle of Willis were healthy and free from atheroma. On dissecting out the three major vessels, the anterior and posterior cerebral arteries appeared normal. The middle cerebral arteries were healthy at their origins. Distal to their first main branches, both vessels were small, white, and thread-like without an obvious lumen. The brain-stem and cerebellum were normal.

\section{Histological Examination}

The infarct in the right insula region has progressed to cyst formation with the wall of the cyst formed by the internal capsule and globus

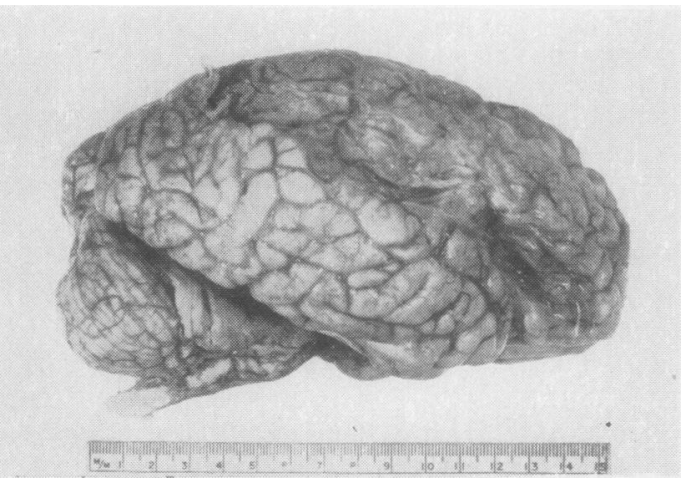

FIG. 1.-Right lateral aspect of brain showing extensive area of old softening around the Sylvian fissure.

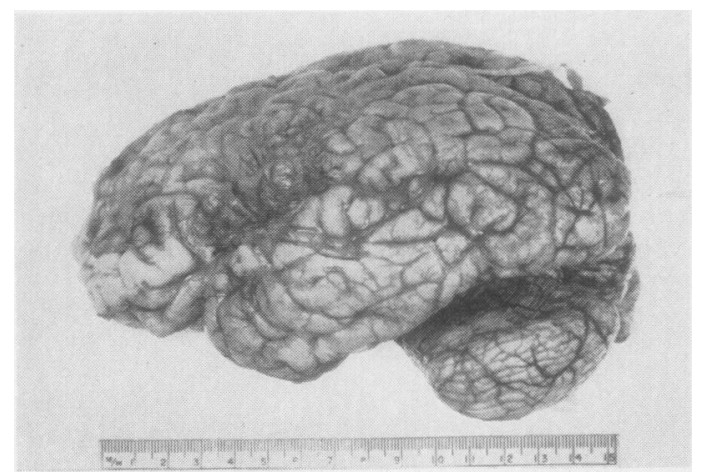

FIG. 2.-Left lateral aspect of brain showing much smaller area of softening.

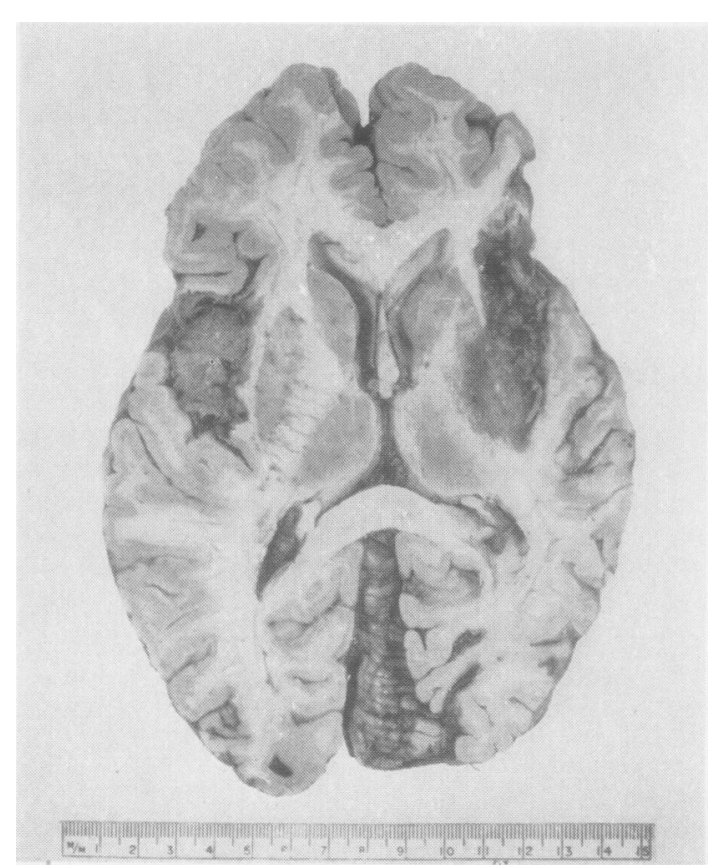

FIG. 3.-Bilateral softenings of the insula region more extensive on the right side.

pallidus. The contents of the cyst have disappeared, but scattered histiocytes and proliferated capillary vessels are present in its margin. There is dense fibrillary gliosis around the affected area, and vessels in the surrounding tissue are cuffed with lymphocytes and a few histiocytes. Many of these cells are present in the overlying thickened pia arachnoid.

A small area of cystic softening, similar in age and appearance, is present on the under surface of the right occipital lobe. This involves the cortex and underlying white matter of the fusiform gyrus with dense gliosis of the surrounding tissue and of the molecular layer of the affected cortex.

The infarcts in the left insula region and on the under surface of the left occipital lobe are much less extensive and of more recent origin. The affected areas are filled with numerous histiocytes and lymphocytes, loosely arranged between proliferated capillary vessels. There is gliosis of the overlying molecular layer of the affected cortex and around the softened areas, but this is much less dense than on the opposite side.

In addition to these large necrotic areas there are scattered small glial scars in the cortex of the right and left superior temporal gyri and in both occipital lobes. In these areas there is loss of nerve cells and dense gliosis. 


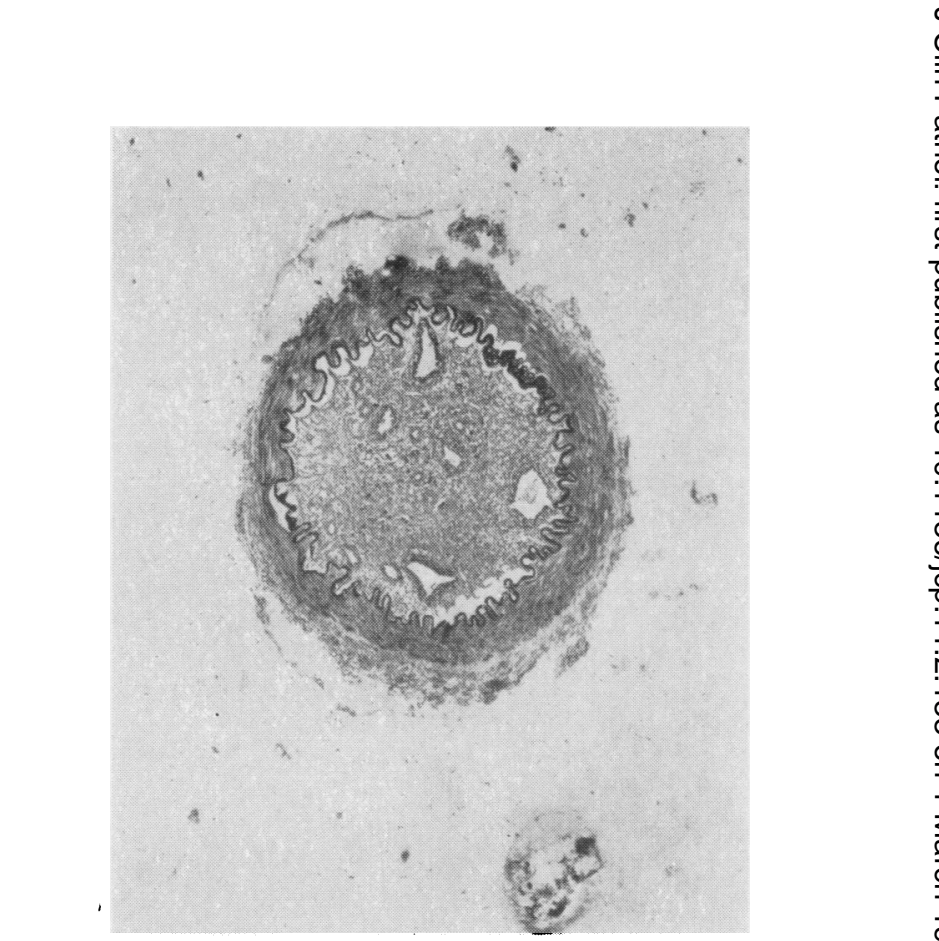

Fig. 4.-Transverse section of the right middle cerebral artery distal to the origin of its first branch. Elastic Masson stain, $\times 35$.

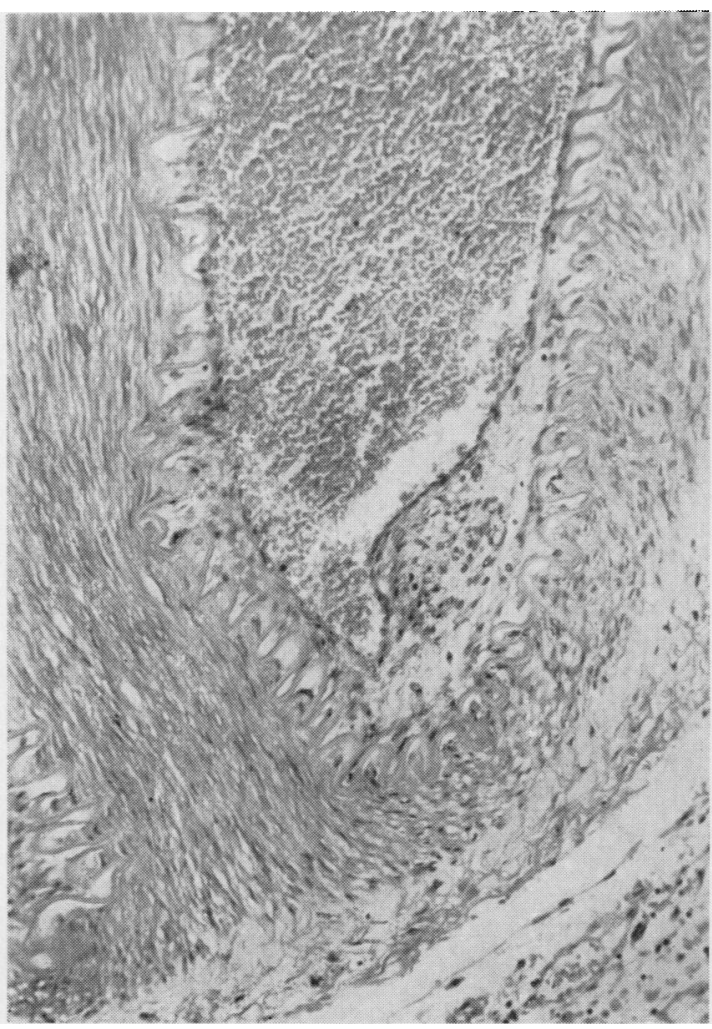

FIG. 6.-Proximal part of the left middle cerebral artery showing subendothelial connective tissue proliferation. Haematoxylin and eosin, $\times 120$.
FIG. 5.-More-distal part of the right middle cerebral artery. Elastic Masson stain, $\times 35$.

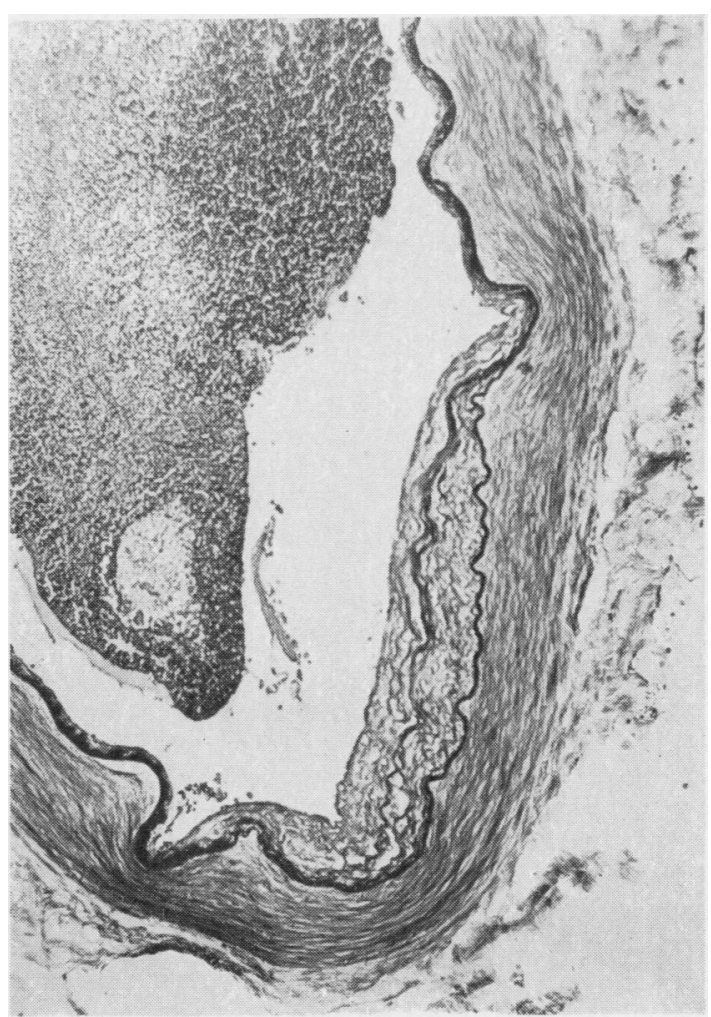

FIG. 7.-Splitting of internal elastic lamina. Proximal part of left middle cerebral artery. Elastic Masson stain, $\times 89$. 
In the brain-stem there is descending degeneration of the cortico-spinal tracts, worse on the right side than on the left.

The right middle cerebral artery beyond the origin of its first branch (Fig. 4) shows recanalized occlusive thrombus, the central mass consisting of swollen fibroblasts amongst which are a few small round cells and occasional histiocytes containing haemosiderin pigment, and including several small, separate, endothelial-lined channels, one of which is occluded with recent fibrin thrombus. The internal elastic lamina is intact, except in one place where it shows reduplication. The media and adventitia appear healthy. These changes extend about $1 \mathrm{~cm}$. along the vessel where the endothelial-lined channels become smaller and fewer (Fig. 5). More distally the lumen of the artery is completely blocked by proliferation of the subendothelial connective tissue of the intima.

The left middle cerebral artery shows similar changes distal to its first branches. The proliferated connective tissue is much more cellular than on the right side with less dense collagen. The most proximal segment of the artery shows a small localized area of subendothelial proliferation (Fig. 6), with fraying and reduplication of the internal elastic lamina (Fig. 7).

The posterior cerebral arteries are healthy, but, over the infarcted areas in the occipital lobe, the terminal branches show severe endarteritis with narrowed lumina (Fig. 8).

Several wedge-shaped scars of dense fibrosis in which fibrosed glomeruli can be recognized are present in the kidneys. No thrombosed vessels are seen and the arteries sectioned appear normal.

The vessels in both pectoral muscles show no evidence of periarteritis nodosa.

\section{Discussion}

Before this case can be accepted as one of cerebral thromboangiitis obliterans without involvement of the peripheral limb vessels, it is necessary to rule out the various other possible causes of cerebrovascular occlusion. There was no previous history of rheumatic fever and the heart showed no evidence of rheumatic disease. The blood pressure was within normal limits on every occasion it was recorded. Although recanalized impacted emboli might give a similar appearance in the cerebral vessels, no possible source of embolic origin for the infarcts was found, while infarction of the same age, as assessed histologically, in the territory supplied by both middle and posterior cerebral arteries does not support this mechanism. Emboli have

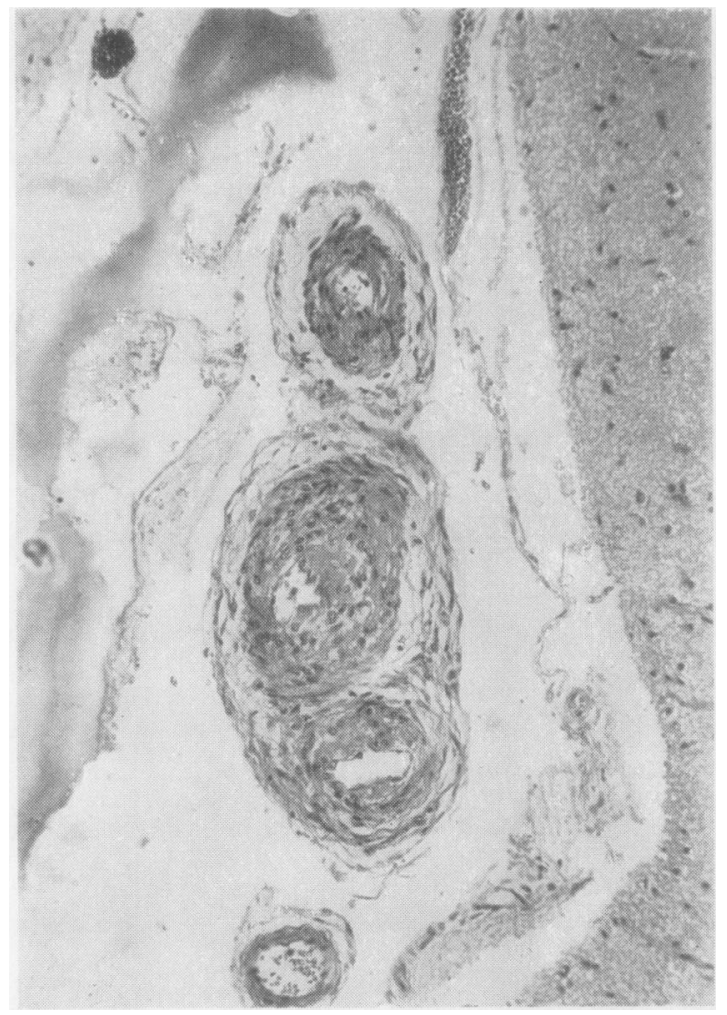

Fig. 8.-Endarteritis of smaller branches of left posterior cerebral artery. Haematoxylin and eosin, $\times 115$.

occurred from the site of the puncture after percutaneous angiography (Crawford, 1956), but this investigation was undertaken after the onset of hemiplegia on each occasion. The age of the patient is against arteriosclerosis, and no evidence of any generalized disease, such as diabetes, syphilis, or tuberculosis, was found. The trauma sustained before the onset of the first symptoms was relatively trivial and could not have damaged the cerebral vessels.

The microscopic changes in the middle cerebral arteries were confined to the intima with preservation of the internal elastic lamina and no inflammatory changes and necrosis, thus favouring thromboangiitis obliterans rather than polyarteritis. The pathological distinction in the later stages between thromboangiitis obliterans and polyarteritis nodosa may be difficult, as in the case reported by Treip and Porter (1957). If hypersensitivity should be the basis of both of these conditions (Llavero, 1948) overlapping of histological lesions may well be possible. Although most authorities regard the histology as distinct, Boyd, Ratcliffe, Jepson, and James (1949) 
questioned the specificity of the pathological findings in thromboangiitis. The original contention of Buerger of the specificity of " purulent giant cell foci " has been denied by many workers, including Koyano (1922) and Krampf (1922). No such foci were found in the present case. No evidence of venous thrombosis was seen, but, as this occurs in only about $30 \%$ of cases of peripheral Buerger's disease (Brown and Henderson, 1927), it is not an essential accompaniment for the diagnosis. Thus, although endarteritis can be part of the pathological process in a number of welldefined conditions (McLetchie and Gillis, 1955), these have been considered and rejected. The opinion of Julitz (1953) that many of these cases are essentially Buerger's disease of widespread, unusual, or variable distribution is accepted.

Although the essential lesions in peripheral vessels were first described by von Winiwarter in 1879 , it was Buerger (1908) who gave the disease the name by which it is generally known. In a subsequent study of these cases, Buerger (1924) described death in some from cerebral complications, but attributed these to arteriosclerosis. It was Cserna (1926) who first described the disease affecting cerebral vessels. Barron and Linenthal (1929) described two cases with hemiplegia and one with basilar thrombosis. Jäger (1932) showed that the vessels of many viscera, including heart, kidneys, stomach, pancreas, and brain, could be affected and stressed the diagnostic importance of the connective tissue filling the lumen of the thrombosed vessel (Füllgewebe). Bauer and Recht (1932) recorded a case with repeated cerebrovascular occlusions. Foerster and Guttmann (1933) made a clinical diagnosis of cerebral thromboangiitis obliterans without reporting on the pathology. Spatz (1935) gave a clear description of the disease involving peripheral and cerebral vessels, but this case is now thought to be one of recurrent emboli.

In the last 20 years many reports have appeared which conclusively establish the existence of the disease in cerebral vessels (Minkowski, 1947-48 ; Llavero, 1948), but there are relatively few histopathological studies concerning the brain changes and confirming the diagnosis. Sträussler, Friedmann, and Scheinker (1937) recorded the pathological details of a case. Hausner and Allen (1938) recorded 11 cases with cerebral symptoms out of 500 with thromboangiitis obliterans of the extremities $(2.2 \%)$. In three of these cases the cerebral symptoms preceded those of peripheral vessel involvement by a varying time interval, the longest period being 14 years. Lindenberg (1939) recorded 22 cases of thromboangiitis obliterans of the brain, in 14 of which the arteries of the extremities were not involved, and Lindenberg and Spatz (1939) described the findings in 20 cases of the cerebral disease. Krayenbühl (1945) reported 25 cases of cerebral thromboangiitis and 11 cases were recorded by Davis and Perret (1947). In a recent survey of Silbert's series, Lippmann (1952) found nine cases of cerebral Buerger's disease in 1,700 cases with peripheral disease. Although Lippmann found over 250 cases of the cerebral disease recorded in the literature, only 30 were acceptable, and these, together with the nine taken from Silbert's series, were reviewed. In 12 of these 39 cases, cerebral symptoms developed before peripheral ones with a time interval of one to five years in eight cases and six to 10 years in three cases, while 20 years was the longest period recorded in one case.

Thus the statement of Klemperer (1943), that there must be a clinical history of involvement of the extremity before a diagnosis of thromboangiitis obliterans in visceral vessels can be accepted, is too rigid and narrow a conception of the disease in view of the well-authenticated cases of cerebral symptoms preceding peripheral ones by a long period of time. In the case described in this paper no peripheral symptoms or pathological changes were found, but as the time of survival was only two years from the onset of the illness it may well be that this was too short a time for more generalized disease to develop.

In many of the recorded cases thrombosis of the internal carotid artery is the principal or sole lesion and the diagnosis has been assumed, either from the absence of other known causes or from the presence of typical lesions in the cerebral arteries in the same case (Antoni, 1941). Stender (1936) found that the anterior and middle cerebral arteries were most often involved, especially the latter. Lippmann (1952) found the internal carotid, vertebral, middle, anterior, and posterior cerebral arteries involved in decreasing order of frequency. The majority of reported cases have been diagnosed at necropsy as in the case recorded here, although Sorgo (1939) and Sunder-Plassmann (1941) described the obliterated cerebral arteries in arteriograms. The angiogram in the present case was reported as normal and subsequent review of the films after the necropsy failed to show any abnormality. In view of the disease affecting the middle cerebral arteries beyond their first branches which were patent and healthy, the normal angiographic appearances can be understood.

Concerning the pathological findings, the gross appearance of the affected arteries resembled the 
description given by Antoni (1941) and Lüers (1942). The microscopical appearance gave no indication of an acute inflammatory process as described by Buerger. No evidence of a primary necrobiotic stage with intramural haemorrhage in the subendothelial tissue between the intima and media was found as described by Scheinker (1944. 1945). The appearance is one of proliferation of endothelial cells of the intima and of the subintimal fibrous tissue corresponding with the second stage described by Scheinker and confirmed by Davis and Perret (1947). The presence of histiocytes filled with blood pigment in the swollen fibroblastic layer may be an indication of old haemorrhage at this site, but the haemosiderin could equally well have originated from degenerate red cells in a thrombus. The scanty lymphocytes were the only indication of a possible inflammatory basis for the condition.

Thus, although the findings in this case are far removed from the concept of the disease originally described by Buerger, they resemble those of a small but well-defined group of cases recorded in the literature and are characterized by typical obliterative arterial disease in the young adult. Even in young males with occlusion of limb vessels, the histological findings may vary considerably from those of classical Buerger's disease with the result that other names such as "nonspecific obliterative angiitis" have been suggested (Pennock and Primas, 1956). Only the reporting of such cases with pathological correlation will clarify the limits of these groups and possibly indicate a more correct terminology.

\section{Summary}

A case of cerebral thromboangiitis obliterans is described in which no evidence of peripheral vascular involvement was found. The clinical features are correlated with the pathological findings and the differential diagnosis is discussed.

The cerebral manifestations of Buerger's disease reported in the literature are briefly reviewed, and the frequency with which these may precede symptoms in the limbs by varying periods of up to 20 years is stressed.

A diagnosis of the condition should be con- 흠 sidered in any case of cerebral thrombosis in a $\frac{\bar{\sigma}}{\vec{D}}$ young adult, where heart disease, arterial de- $\stackrel{\mathbb{Q}}{\varrho}$ generation, and generalized systemic disease cannot be found, and demyelinating disease can be excluded.

My thanks are due to Mr. James Hardman. F.R.C.S., under whose care this case was admitted, $\bar{O}$ for allowing full access to his notes and for much? advice, and to Professor D. H. Collins for helpful $\overrightarrow{\vec{H}}$ criticism.

\section{REFERENCES}

Antoni, N. (1941). Acta med. scand., 108, 502.

Barron, M. E., and Linenthal, H. (1929). Arch. Surg. (Chicago), 19,

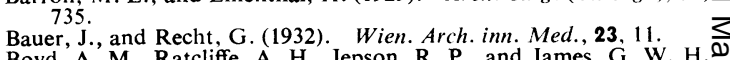

Boyd, A. M., Ratcliffe, A. H., Jepson, R. P., and James, G. W. H.气 (1949). J. Bone Jt Surg., 31 B, 325.

Brown G. E and Henderson, M. S. (1927). Ibid, 9, 613.

Buerger, L. (1908). Trans. Ass. Amer. Phys., 23, 200. (1924). The Circulatory Disturbances of the Extremities, Ch. $63, \overrightarrow{0}$ p. 368. Saunders, Philadelphia.

Crawford, T. (1956). J. Neurol. Neurosurg. Psychiat., 19, 217.

Cserna, S. (1926). Wien. Arch. inn. Med., 12, 213.

Davis, L., and Perret, G. (1947). Brit. J. Surg., 34, 307.

Foerster, $\mathrm{O}$ and Guttmann, L. (1933). Arch. Psychiat. Nervenk $100,506$.

Hausner, E., and Allen, E. V. (1938). Ann. intern. Med., 12, 845

Jäger, E. (1932). Virchows Arch. path. Anat., 284, 526.

Julitz, R. (1953). Z. ges. inn. Med., 8, 343.

Klemperer, P. (1943). Proc. N.Y. path. Soc., 1942-1945, p. 54

Koyano, K. (1922). Acta Sch. med. Univ. Kioto, 4, 489.

Krampf, F. (1922). Dtsch. Z. Chir., 174, 387.

Krampr, Fi (1922. (1945). Schweiz. med. Wschr., 75, 1025.

Krayenbühl, H. (1945). Schweiz. med. Wschr,, 75, 1025.

Lindenberg, R. (1939). Z. ges. Neurol. Psychiat., 167, 554. 3051.

Lippmann, H. I. (1952). Circulation, 5, 680.

Llavero, F. (1948). Thromboendangititis obliterans des Gehirns? Benno Schwabe, Basel.

Lüers, T. (1942). Arch. Psychiat. Nervenkr., 115, 319.

(1955). Amer. J clin Path 25,502 .

Minkowski, M. (1947-48). Confin. neurol. (Basel), 8, 138.

Pennock, L. L., and Primas, H. D. (1956). Angiology, 7, 32.

Scheinker, I. M. (1944). Arch. Neurol. Psychiat. (Chicago), 52, 27. (1945). J. Neuropath., 4, 77.

Sorgo, W. (1939). Z Zbl. Neurochir., 4, 161.

Spatz, H. (1935). Dtsch. Z. Nervenheilk., 136, 86.

Stender. A. (1936). Z. ges. Neurol. Psychiat., 156, 761.

Stender, A. (1936). Z $Z$. ges. Neurol. Psychiat., 156, 761.
Sträussler, E., Friedmann, R., and Scheinker, J. (1937). Ibid., 160,

$$
155 .
$$

Sunder-Plassmann, P. (1941). Dtsch. Z. Chir., 254, 463.

Treip, C. S., and Porter, K. J. (1957). J. Neurol. Neurosurg Psychiat., 2u, 50.

Winiwarter, F. von (1879). Arch. klin. Chir., 23, 202. 